\title{
Control of Pulsatile Insulin Secretion in Man
}

\author{
D. R. Matthews, D.A. Lang, M. A. Burnett and R. C. Turner \\ Diabetes Research Laboratories, Radcliffe Infirmary, Oxford, UK
}

\begin{abstract}
Summary. Plasma insulin and glucose concentrations were examined in man in a basal state from central venous samples taken at 1-min intervals for up to $2.5 \mathrm{~h}$. Normal subjects have insulin oscillations of mean period $14 \mathrm{~min}$ (significant autocorrelation, $p<0.0001$ ) with changes in concentration of $40 \%$ over $7 \mathrm{~min}$. The pulsation frequency was stable through cholinergic, endorphin, $\alpha$-adrenergic or $\beta$-adrenergic blockade, or small pertubations with glucose or insulin. Stimulation of insulin secretion by intravenous glucose, tolbutamide or sodium salicylate increased the amplitude of the insulin oscillations while the frequency remained stable. Patients with a truncal vagotomy or after Whipple's operation had longer-term oscillations of 33 and $37 \mathrm{~min}$ periodicity (autocorrelation: $p<$ 0.0001 ), with insulin-associated glucose swings four times
\end{abstract}

larger than those of normal subjects. Type 2 (non-insulin-dependent) diabetic patients had a similarly increased insulinassociated glucose swing of six times that seen in normal subjects. The hypothesis is proposed that the 14-min cycle of insulin production is controlled by a 'pacemaker' which assists glucose homeostasis. The longer 33-37-min oscillations, seen in those with denervation, may arise from a limit-cycle of the feedback loop between insulin from the B cells and glucose from the liver. The vagus may provide hierarchical control of insulin release.

Key words: Insulin, Type 2 diabetes, oscillations, pulsations, man, vagotomy, pacemaker, atropine, naloxone, phentolamine, propranolol, glucose, tolbutamide, sodium salicylate.
In the basal state, plasma concentrations of insulin oscillate about a mean value in rhesus monkeys $[1,2]$, baboons [3] and man [4-7] with a periodicity of 8-14 min. Oscillations of pancreatic output of insulin of similar time course have also been observed in vitro using a canine pancreas preparation perfused at a constant glucose concentration [8], suggesting that the oscillatory stimulus arises in the pancreas.

The control of these pulsations is of interest as Type 2 (non-insulin-dependent) diabetic patients do not have the regular cycles that are found in normal subjects [9], and manipulating oscillations may be an alternative method of enhancing insulin's effect. The pulsations imply that islets secrete insulin synchronously and are co-ordinated, as the organ is about $20 \mathrm{~cm}$ long in dogs [8] and $15 \mathrm{~cm}$ long in man [10]. Possible mechanisms of such co-ordination include the extensive neural network between the islets [11-13], or an intrapancreatic 'paracrine' system such as the inhibition of insulin by insulin [14] or C-peptide [15], or a more complex relationship involving somatostatin [16]. Glucagon oscillates nearly in phase with insulin [7], and may be consequently involved in the control pathway, or its re- lease may be controlled by a similar mechanism to insulin.

The present study investigated the role of the neural network in man by inducing pharmacological changes of $\alpha, \beta$, cholinergic or endorphine receptors and examining the effect on the oscillations. In addition the effects on the oscillations of several B cell-stimulating agents were investigated, and pulsations were analysed to examine the possibility of cycle 'resetting'. Groups of patients with truncal vagotomy or with surgical pancreatic denervation were studied in a basal state, and comparable data are presented from a group of diabetic patients previously reported [9]. The influence of insulin pulsations on glucose homeostasis has also been examined.

\section{Subjects and Methods}

Subjects were studied in the morning after an overnight fast. Normal subjects were all in good general health; their age range was 20-39 years and there was a preponderance of male subjects ( 35 males, $11 \mathrm{fe}$ - 
Table 1. Details of regular insulin oscillations analysed by correlogram in nine normal subjects

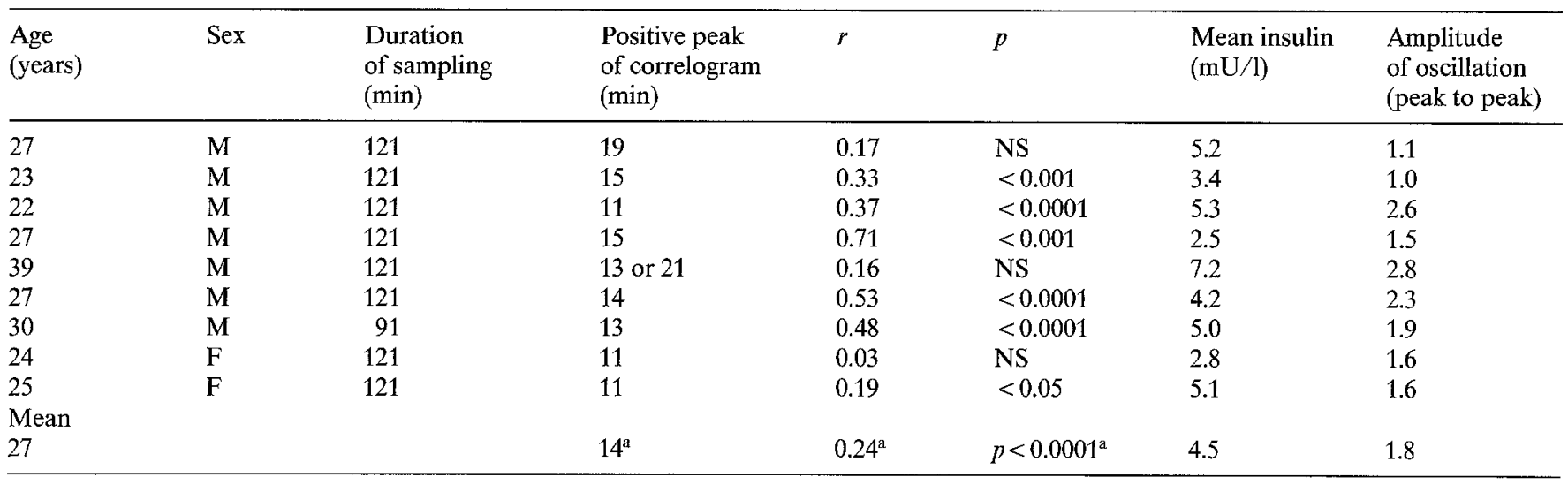

$\mathrm{NS}=$ not significant $; \quad{ }^{\mathrm{a}}=$ Fisher's $\mathrm{Z}$ transformation

males). The 12 Type 2 diabetic subjects studied (10 males and two females, age range 40-67 years) were all treated by diet alone with no known complications of their disease. Six symptom-free subjects, who had previously had truncal vagotomy after recurrent duodenal ulceration, were studied (five males, one female: age 38-71 years). The mean time from vagotomy was 4 years. Two patients were studied after a Whipple's operation for neoplasm in the head of the pancreas. Both had an intact body and tail of pancreas, were healthy and thought to be free of neoplasm.

After an overnight fast, a 24-in. double-lumen IV cannula was inserted in the antecubital vein using local anaesthesia. It was fed into the region of the superior vena cava or subclavian vein and kept patent using $0.154 \mathrm{~mol} / 1$ saline. After insertion, blood was taken through the inner lumen at a constant rate of $2 \mathrm{ml} / \mathrm{min}$ by a rotary pump. The samples were prevented from clotting by the use of $0.02 \mathrm{ml} / \mathrm{min}$ of calcium-heparin in saline $(1250 \mathrm{IU} / \mathrm{ml})$ pumped through the outer lumen at a constant rate. The experiments were performed in a quiet room and the subjects encouraged to sleep.

The studies lasted up to $150 \mathrm{~min}$. In the infusion studies, the first $60 \mathrm{~min}$ were used as a control period followed by $45-60 \mathrm{~min}$ infusion, with a final recovery period. One experiment involved a short pulse of $0.5 \mathrm{~g}$ glucose at $60 \mathrm{~min}$ followed by $0.1 \mathrm{U}$ insulin (Actrapid, Novo) at $105 \mathrm{~min}$.

In the infusion studies undertaken on normal subjects one of the following pharmacological agents was used: Blockade: cholinergic blockade by atropine $1.2 \mathrm{mg}$ IV followed by an infusion of $0.9 \mathrm{mg}$; endorphine-blockade by naloxone $0.3 \mu \mathrm{g} \cdot \mathrm{kg}^{-1} \cdot \mathrm{min}^{-1} ; \alpha$-adrenergicblockade by phentolamine $4-7 \mu \mathrm{g} \cdot \mathrm{kg}^{-1} \cdot \mathrm{min}^{-1} ; \beta$-adrenergic-blockade by propanolol $2 \mathrm{mg}$ IV followed by an infusion of $2 \mathrm{mg}$. Stimuli: glucose infusion $1.5 \mathrm{mg} \cdot \mathrm{kg}^{-1} \cdot \mathrm{min}^{-1}$; tolbutamide infusion $7 \mathrm{mg} / \mathrm{m}^{2}$ per min; sodium salicylate $40 \mathrm{mg} / \mathrm{min}$.

Plasma glucose was assayed using an automated glucose oxidase method (Pye Unicam, Cambridge, UK, precision $\mathrm{SD}=0.08 \mathrm{mmol} / \mathrm{l}$ ). Charcoal phase separation radioimmunoassay [17] was used for plasma insulin (precision SD $1.1 \mathrm{mU} / 1$ ). Calculations and statistics were performed on a CTL/8050 computer (Computer Technology, Hemel Hempstead, UK). These experiments were passed by the Oxford Area Health Authority Sector Ethical Committee.

\section{Data Analysis}

Minimising random error: The signal-to-noise ratio was improved by undertaking all assays in duplicate, and then using a 3 min moving average [18-20] which allowed six assay values to be used to estimate each point. Moving averages give a greater precision to each value, at the expense of making time trends less obvious and reducing the amplitude of such changes.
Validation of time-series data: The time-series nature of the data was analysed statistically by determining the frequency of data-runs each side of the median $[21,22]$.

Examining repeatable patterns by autocorrelation: Regular oscillations in the plasma insulin concentration were sought by autocorrelation [18]. This involves time series data being correlated with an exact duplicate of itself and the time series being moved stepwise by minute intervals and correlated again. The initial correlation is, by definition, +1 and the serial values of $\mathrm{r}$ fall until they reach a nadir when the data are $180^{\circ}$ out of phase. The first significantly positive peak $(p<$ $=0.05$ after Fishers $Z$ transformation [23]) represents the period of any regularly recurring cycle and the $Z$-transformation was used to sum the data from different subjects [23]. Cross-correlation is a similar technique, where one data set is compared with another: in this case positive correlations can be a marker of phase changes provided the data are 'stationary' (vide infra) $[18,19]$. The relative amplitude of the changes of one variable can be calculated from the root-mean change of the other multiplied by the slope of the regression line.

Longer term trends: Short-term oscillations can be obscured by longterm trends and in time series analysis allowance can be made by removal of the trends to make the data 'stationary' [18-20]. In practice this usually involves examining oscillations about the trend-line of the data, rather than examining absolute values. We examined the variations about the least square regression lines on the data sets.

Sine-wave fitting: This was achieved by iterative change of both origin and period (defined initially from autocorrelation) to achieve leastsquare deviation of the data-set.

Amplitude of oscillations: The mean amplitude of the oscillations was calculated as the root-mean square of the moving average data $\times 2 \sqrt{2}$. This gives a precise estimate for sine-wave [24] data and is a near-approximation with other wave-forms. The precison of glucose homeostasis was calculated as the confidence limits within which $95 \%$ of glucose values fell. Differences were assessed by calculation of $F$ values [25].

\section{Results}

The time-series nature of the data was verified in 52 of 54 insulin data sets from the normal subjects, and in 10 of 12 insulin data sets from the Type 2 diabetic patients. 


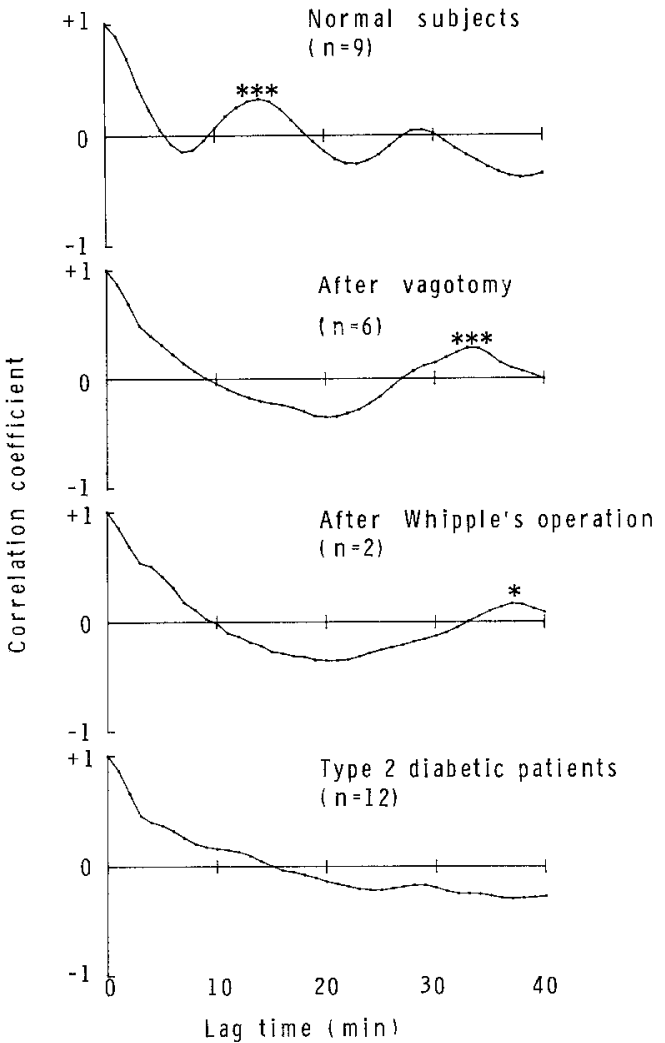

Fig. 1. Serial correlation coefficients obtained from correlating insulin data arrays with an identical 'copy' at the lag time shown by the horizontal axis. Results are pooled for subjects (number shown as $n$ ) by Fisher's $\mathrm{Z}$ transformation. ${ }^{* * *} p<0.0001 ;{ }^{*} p<0.05$

\section{Normal Subjects}

Plasma insulin oscillations were analysed for a minimum of $90 \mathrm{~min}$ in nine fasting normal subjects (Table 1). Regular insulin oscillations analysed by autocorrelation of the linearly stationary data showed a distribution of the first positive peaks of individual correlograms between 11 and 21 : three subjects had no significant positive peak in their correlogram. Summation of all nine correlograms by Fisher's Z (Fig.1, top panel) showed a significantly overall regular periodicity of $14 \mathrm{~min}(r=0.24, p<0.0001)$ of amplitude $1.8 \mathrm{mU} / 1$ (peak to peak) on a mean of $4.5 \mathrm{mU} / 1$, indicating an average change of insulin concentration of $40 \%$ over $7 \mathrm{~min}$ (half of the period). The stability of the glucose was estimated by the $95 \%$ confidence limits of values about the mean and was $4.17 \pm 0.23 \mathrm{mmol} / \mathrm{l}$.

\section{Blocking Agents (Fig. 2)}

Cholinergic blockade: The cholinergic blocking drug, atropine, was administered as either a bolus or bolus + infusion, and vagal blockade was demonstrated by a tachycardia, the pulse-rate increasing from an average of $55-92 / \mathrm{min}$. The pulsations of insulin continued unchanged both in period and amplitude (F-test: NS), though after the bolus of atropine was given, the mean

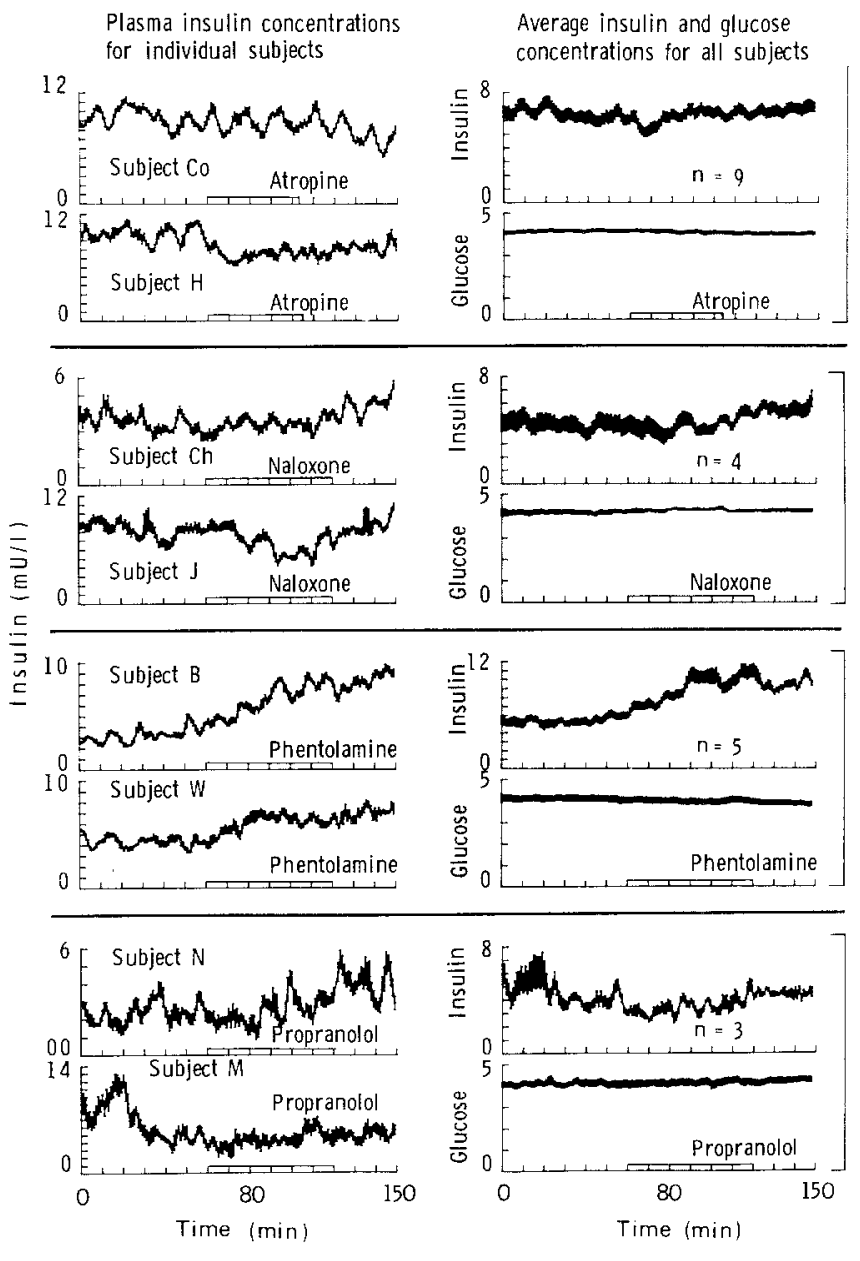

Fig. 2. Three-minute moving average \pm SEM from samples taken at 1-min intervals assayed in duplicate. Left panel: data from individual subjects. Right panel: pooled data. Number of subjects is shown as $n$. Open panel boxes: infusion period. Right panel vertical axis: alternating insulin $(\mathrm{mU} / \mathrm{l})$ and glucose $(\mathrm{mmol} / \mathrm{l})$ concentrations

plasma insulin concentration fell from 6.5 to $5.5 \mathrm{mU} / 1$, $6 \mathrm{~min}$ later $(p<0.01)$, recovering over the next $10 \mathrm{~min}$. There was no concomitant plasma glucose trend.

Endorphin receptor blockade: Naloxone had no effect on the period of the oscillations, but the amplitude of the oscillations increased nearly twofold $(\times 1.96$; F-test $p<0.0001)$. The mean plasma insulin concentration increased over $1.5 \mathrm{~h}$ from 4.4 to $5.8 \mathrm{mU} / 1(p<0.0001)$, but was not accompanied by any significant change in plasma glucose concentration.

$\alpha$-adrenergic blockade: Phentolamine infusion had no detectable effect on the periodicity of insulin pulsations. The amplitude of the oscillations increased twofold $(\times 2.17$; F-test, $p<0.0001)$ while the mean plasma insulin concentration increased from 5.4 to $9.0 \mathrm{mU} / 1$ $(p<0.0001)$. The mean plasma glucose concentration dropped progressively from 4.1 to $3.9 \mathrm{mmol} / 1(p<$ 0.001 ), indicating that the insulin rise was not secondary to a hyperglycaemic stimulus. 


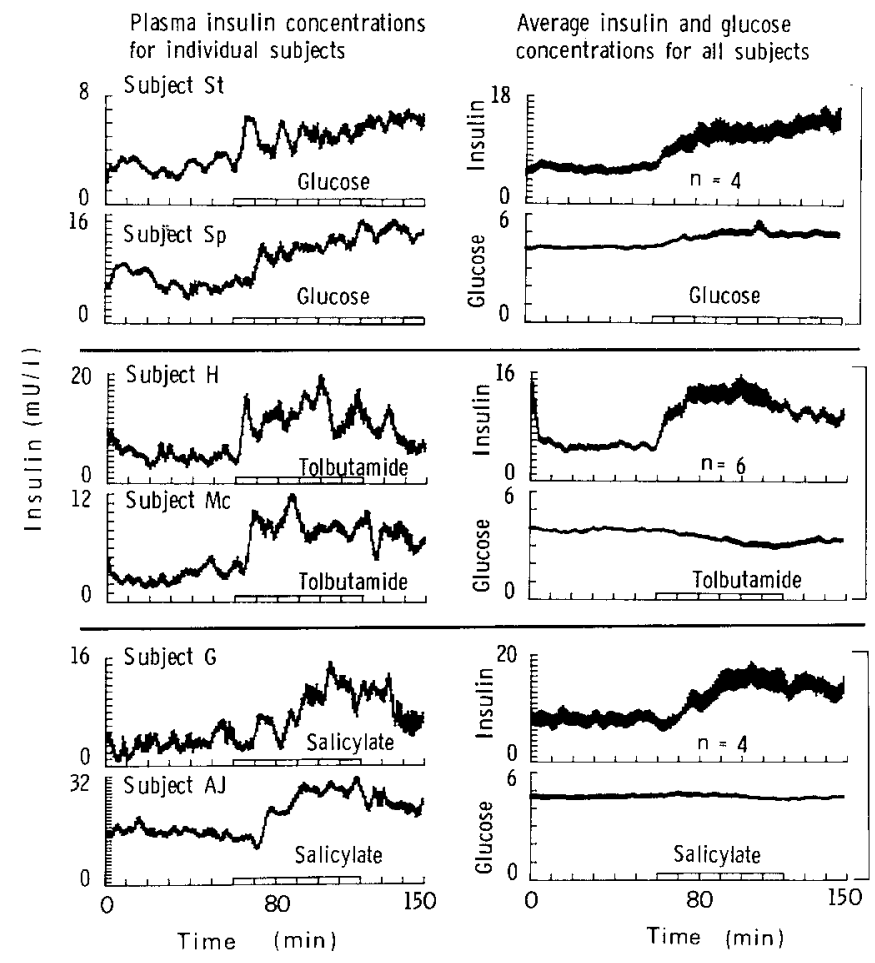

Fig. 3. Three-minute moving average \pm SEM from samples taken at 1-min intervals assayed in duplicate. Left panel: data from individual subjects. Right panel: pooled data. Number of subjects is shown as $n$. Open boxes: infusion period. Right panel vertical axis: alternating insulin $(\mathrm{mU} / \mathrm{l})$ and glucose $(\mathrm{mmol} / \mathrm{l})$ concentrations
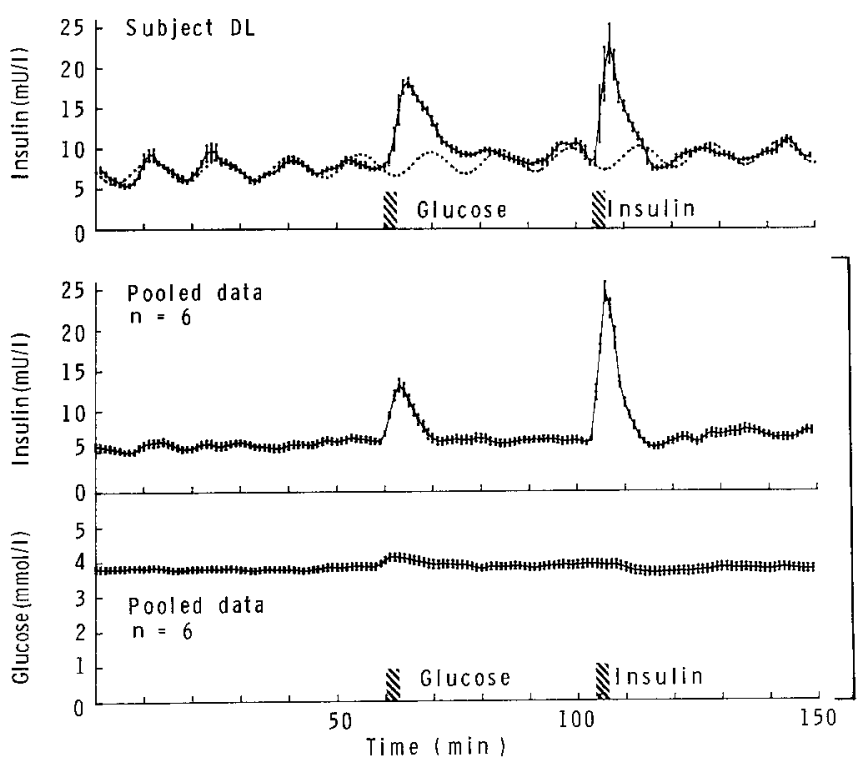

Fig.4. Three-minute moving average \pm SEM from samples taken at 1-min intervals assayed in duplicate. Upper panel: data from one subject. Lower panels: pooled data from six subjects. : glucose $0.5 \mathrm{~g}$ and insulin $0.1 \mathrm{U}$ given as bolus

$\beta$-adrenergic blockade: There was no change in the periodicity of insulin oscillations after propranolol, but a decrease in the amplitude of the oscillations $(\times 0.78$; $p<0.0001)$. The mean plasma insulin concentration fell from 4.6 to $3.8 \mathrm{mU} / 1(p<0.001)$. There was no significant trend in the plasma glucose concentration.

\section{B Cell Stimulation (Fig. 3)}

Glucose: Following glucose infusion, the insulin oscillation period, as estimated by pooled correlograms, did not significantly alter, but the amplitude increased from a mean of 1.7 to $4.2 \mathrm{mU} / 1(p<0.0001)$. There was an increase of mean plasma insulin from 5.8 to $11.9 \mathrm{mU} / 1$ $(p<0.001)$ as the plasma glucose increased from a mean of 4.2 to $4.9 \mathrm{mmol} / 1$.

Tolbutamide: During tolbutamide infusion, the insulin oscillation period did not significantly alter, but the amplitude increased from mean 2.3 to $8.7 \mathrm{mU} / 1(p<$ 0.0001 ) with a change in the mean plasma insulin concentration from 5.7 to $12.0 \mathrm{mU} / 1(p<0.0001)$. The plasma glucose showed a declination over the time period of the hyperinsulinaemia from 3.9 to $3.4 \mathrm{mmol} / 1(p<$ 0.0001 ).

Sodium salicylate: During infusion of sodium salicylate the insulin oscillation period did not significantly alter but the oscillation amplitude increased by nearly three fold within $10 \mathrm{~min}$ of the onset of the infusion from a mean peak to peak of 2.6 to $7.1 \mathrm{mU} / 1(p<0.0001)$. Similarly the mean plasma insulin concentration increased from 8.0 to $13.1 \mathrm{mU} / 1(p<0.0001)$ with no concomitant fall in the prevailing glucose concentration - mean 4.65 to $4.64 \mathrm{mmol} / 1$ (NS).

\section{Cycle 'Resetting' or Cycle Continuity?}

Non-glucose stimuli: There was no evidence from pooling the data from the time of beginning the above infusions that any of the B cell stimuli caused 'resetting' of the oscillations. Such a resetting would cause synchronous excursions for at least two cycles from the 'reset' point, but this was not observed.

Glucose pulse and insulin pulse (Fig. 4): In six subjects, who received a $0.5 \mathrm{~g}$ bolus of glucose, there was a second peak of insulin $18 \mathrm{~min}$ after the initial insulin peak, which occurred with a prevailing mean plasma glucose concentration $0.12 \mathrm{mmol} / 1$ above basal. This probably therefore reflects a 'second phase' insulin response, though it is impossible to distinguish this from an oscillatory response on current data. The IV insulin pulse did not synchronise or suppress oscillations. It seems, however, from examination of the data from subjects in whom the cycles were very regular that there was a continuation of the endogenous pulsations regardless of small glucose or insulin perturbations. Such a subject's data are shown in Figure 4 where the best-fitting sinewave has been plotted to the basal data (the first four and last positive peaks) and extended through the experimental data to indicate the expected oscillations if there had been no perturbations: endogenous pulsations seem to continue with the same periodicity. 


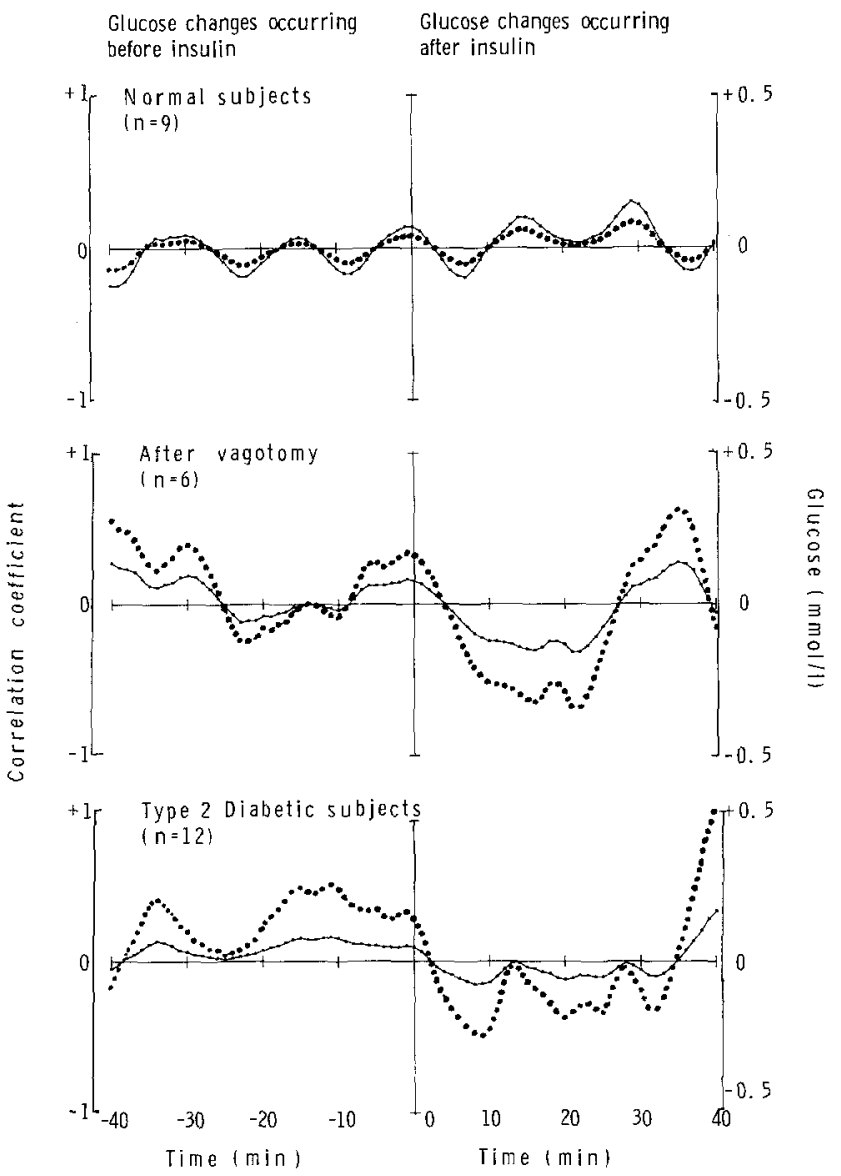

Fig. 5. Serial correlation coefficients (- $\longrightarrow$ ) obtained from correlating insulin with glucose at lag time shown. Positive correlations show data in phase and negative correlation data out of phase. The results can be interpreted by regarding the insulin data as stationary and the correlation coefficient as expressing the mean-insulin-associatedglucose-change for any given time-lag before or after insulin. The zero time point represents the correlation between the simultaneous insulin and glucose arrays when compared directly. The correlation coefficient represents the strength of association between the two variables, but does not express the magnitude of the change. The dotted line (...) on the cross correlations show the comparative magnitude of plasma glucose deviation from the mean at any given time before or after the plasma insulin, expressed in mmol/1. Results are pooled by Fisher's $Z$ transformation. Number of subjects is shown as $n$

\section{Vagotomised Patients}

Two vagotomised subjects showed regular plasma insulin oscillations in the normal range having autocorrelogram peaks at 13 and $17 \mathrm{~min}$. Three subjects had longer periodicities and one subject had irregular changes. The summed autocorrelograms for the vagotomised subjects studied for $2 \mathrm{~h}$ showed an overall periodicity of $33 \mathrm{~min}$ $(r=0.27 p<0.0001)$ (Fig. 1, second panel). Two patients, who had had Whipple's operation, were studied in a basal state, and they also demonstrated longer term oscillations with a mean period of $37 \mathrm{~min}(r=0.17 ; p<0.05$; Fig.1, third panel). The stability of the glucose was estimated by the $95 \%$ confidence limits of values about the mean, and was $4.56 \pm 0.34 \mathrm{mmol} / 1$.

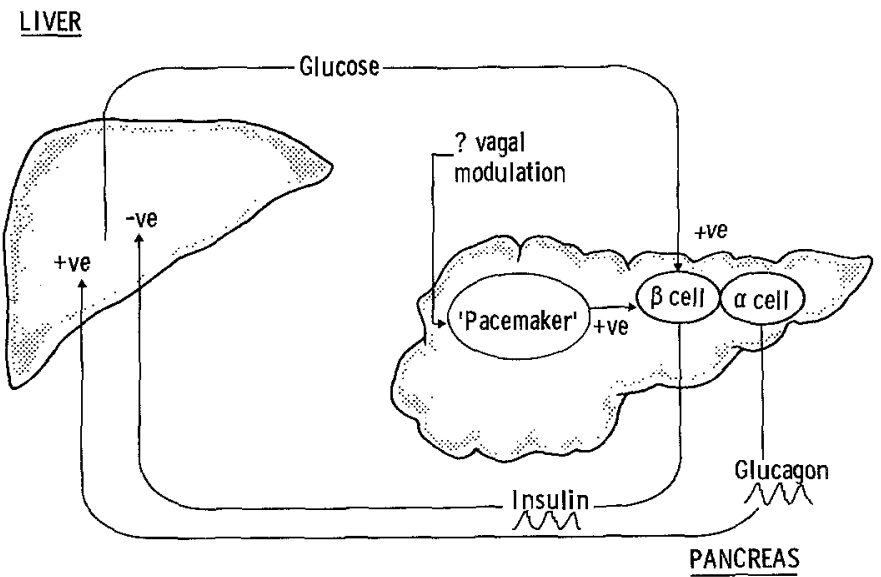

Fig.6. Hypothesis of a pacemaker controlling the 14-min stable endogenous insulin and glucagon secretion from the pancreas within a slower acting 30-40 min limit cycle of a feed-back loop between the liver/periphery and pancreas. Vagotomy allows the latter control to become dominant. + ve and -ve indicate the positive and negative effects

\section{Diabetic Patients}

Data for diet-treated Type 2 diabetic patients have been reported previously [9]. Persistently regular cycles were not observed, and this is reflected in the absence of a positive peak in the correlogram (Fig. 1, bottom panel), either at $14 \mathrm{~min}$ as in normal subjects, or at $30-40 \mathrm{~min}$ as in patients who have had a total vagotomy or Whipple's operation. The stability of the plasma glucose, estimated as the mean and $95 \%$ confidence limits was $6.96 \pm$ $0.32 \mathrm{mmol} / \mathrm{l}$.

\section{Correlations Between Glucose and Insulin Changes}

The inter-relationships between the insulin and glucose changes were examined by cross-correlation for the normal subjects, those who had truncal vagotomy and the group of diabetic subjects. The technique examines the phase relationships of glucose and insulin fluctuations by expressing the correlation-coefficient between the variables at different 'lag' times. Figure 5 (upper panel) shows the cross-correlation between glucose and insulin in normal subjects. Correlation peaks occurred when the glucose array was advanced 15 or $30 \mathrm{~min}$ before insulin or lagged 14 or $29 \mathrm{~min}$ after the insulin array. Such a repeating pattern indicates that the 14-min oscillatory period of the insulin was paralleled by glucose changes. The positive cross-correlation at zero time (when the arrays were neither advanced nor lagged) shows that the two were in phase. The dotted line (representing the magnitude of the insulin-associated glucose change) shows that in normal subjects there was a very small change from the mean. By contrast, subjects after truncal vagotomy showed slow trends (Fig. 5, middle panel): there was a positive correlation of glucose against insulin for $9 \mathrm{~min}$ before the insulin followed by a large inverse change, and subsequent re-iteration 
some $30-40 \mathrm{~min}$ later. The amplitude (dotted line) of the glucose change was four times that of normal subjects. Diabetic patients (Fig. 5, lower panel) had an even longer positive cross-correlation before the insulin, with an insulin-associated peak glucose change six times that of normal subjects.

A conceptualisation of these data can be made as follows: for an insulin peak occurring at time zero, normal subjects had a small prior increased glucose exposure amounting to a mean of $0.025 \mathrm{mmol} / 1$ glucose for $4 \mathrm{~min}(0.1 \mathrm{mmol} / 1 \cdot \mathrm{min})$; those with vagotomy had a larger and longer exposure of a mean increase of $0.11 \mathrm{mmol} / 1$ glucose for $8 \mathrm{~min}(0.9 \mathrm{mmol} / 1 \cdot \mathrm{min})$; while diabetics had a $25 \mathrm{~min}$ exposure of mean rise $0.16 \mathrm{mmol} / 1$ glucose $(3.9 \mathrm{mmol} / 1 \cdot \mathrm{min})$.

\section{Discussion}

Short-term pulsations of hormone concentration are not unique to insulin. They have been described with leuteinising hormone [26], arginine vasopressin [27], oxytocin [28], gonadotrophin releasing hormone [29], $\mathrm{ACTH}$, corticosteroids and human growth hormone [30]. Oscillation of basal plasma insulin concentrations have previously been documented in rhesus monkeys [1], baboons [3] and man [4-7, 9, 31, 32]. C-peptide measurements, glucose infusion studies [5,9] and work on isolated perfused dog pancreas [8] suggested that there is an endogenous pacemaker, and that the shortterm oscillations were not a limit-cycle of a feed-back loop.

The data presented here show that in man in the basal state there is more precise glucose homeostasis in normal subjects with 14-min insulin oscillations than in those with truncal vagotomy or after a Whipple's operation. Both latter groups showed a tendency to have longer term oscillations (period 33 and $37 \mathrm{~min}$ ), compared with normal subjects. We propose the hypothesis that the longer period might represent the period of the dynamic feed-back limit-cycle between the liver/periphery and the B cell. In accord with this is the demonstration of an 8 min positive cross-correlation of the plasma glucose before the plasma insulin in patients with truncal vagotomy, and the feed-back kinetics of a mathematical model [33] can be shown to have an intrinsic periodicity of about $40 \mathrm{~min}$ [32]. Cross-correlations in data from Type 2 diabetic patients showed a 39 times greater than normal glycaemic exposure before plasma insulin changes, in keeping with the decreased B cell sensitivity for glucose, but not previously demonstrated in the basal state. Cross-correlations are supportive evidence and not proof of causation.

The control of the pacemaker is of potential importance in view of its apparent dysfunction in diabetic patients [9]. In normal man it appears that neither cholinergic, $\alpha$ - or $\beta$-adrenergic or endorphine blockade affects the periodicity of the oscillations, nor could the increased insulin secretion induced by glucose, tolbu- tamide or salicylate be demonstrated to reset the timing. Thus the pacemaker itself is not affected by factors which alter insulin secretion. As a corollary, all stimuli of insulin secretion were shown to increase the amplitude of pulsations, varying from a $96 \%$ amplitude increase with naloxone (for a $28 \%$ increase in the mean plasma insulin), a $120 \%$ amplitude increase with phentolamine (for a $68 \%$ rise), a $150 \%$ amplitude increase with glucose (for $105 \%$ mean rise) and $280 \%$ amplitude increase for tolbutamide (for a 110\% mean rise).

Pacing stimuli may either emanate from the central nervous system or the vagus may modulate the intrinsic pancreatic pacemaker with hierarchical control in a similar way to its modulation of the intrinsic pacemaker of the sino-atrial node of the heart. Evidence that general anaesthesia does not suppress oscillations in monkeys [34] does not rule out a neuronal modulation. The lack of pulsations following a Whipple's operation might signify that the pacemaker is in the pancreatic head, and lack of effect of $\alpha$-adrenergic, $\beta$-adrenergic, cholinergic or endorphine blockade suggests the network from the pacemaker to the B cells is not mediated by such receptors. One cannot exclude other transmitters such as dopamine or the peptidergic neurones reported within the pancreas [12].

Whilst the increased insulin secretion induced by tolbutamide, phentolamine or naloxone appeared to lower the plasma glucose concentration, salicylate failed to have a similar effect. Possible explanations include salicylate stimulation of hepatic glucose efflux, increased glucagon secretion or stimulation of ACTH and cortisol [35].

In conclusion, the pacemaker, which controls insulin secretion in man, is remarkably stable. Its periodicity is not affected when insulin secretion is stimulated by glucose, tolbutamide, $\alpha$-adrenergic blockade or endorphine blockade. Although atropine does not affect the pulsatility, patients who have had a vagotomy do not have a similar dominant 14-min cycle. The pacemaker functions within the context of a feed-back loop between the liver/periphery and the B cells (Figure 6), and after vagotomy there is less precise basal plasma glucose control. An oscillator within a feed-back loop is known to engineers as a method of maintaining a dynamic readiness for external stimuli, with increased sensitivity to changes from the norm [36].

Acknowledgements. We acknowledge helpful discussions with Professor T. Brooke Benjamin, Department of Mathematics, Oxford and we are indebted to him for the mathematical analysis of the periodicity of the limit cycle of the feed-back loop between the liver and pancreas. We are grateful to Ms. B.A. Naylor for laboratory and computing help. Thanks are due to the Charles Wolfson Charitable Trust for a grant towards this project. D. R. Matthews is a Nuffield Research Fellow at Balliol College.

\section{References}

1. Goodner CJ, Walike BC, Koerker DJ, Ensinck JW, Brown AC, Chideckel EW, Palmer L, Kalnasy L (1977) Insulin, glucagon and 
glucose exhibit synchronous, sustained oscillations in fasting monkeys. Science 195: 177-179

2. Koerker DJ, Goodner CJ, Hansen BW, Brown AC, Rubenstein AH (1978) Synchronous sustained oscillation of C-peptide and insulin in the plasma of fasting monkeys. Endocrinology 102: $1649-1652$

3. Steiner RA, Stewart JK, Barber J, Koerker D, Goodner CJ, Brown A, Illner P, Gale CC (1978) Somatostatin: A physiological role in the regulation of growth hormone secretion in the adolescent male baboon. Endocrinology 102: 1587-1594

4. Matthews DR, Lang DA, Peto J, Turner RC (1978) Cyclical variation (Hunting) of basal plasma glucose and insulin concentrations in normal and diabetic man. Diabetologia 15: 254 (Abstract)

5. Lang DA, Matthews DR, Peto J, Turner RC (1979) Cyclic oscillations of basal plasma glucose and insulin concentrations in human beings. N Engl J Med 301: 1023-1027

6. Hansen BC, Jen CK-L, Wolfe RA (1979) Effects of over-feeding and obesity on rapid oscillatory patterns of insulin secretion in rhesus monkeys. Fed Proc 38: 878 (Abstract)

7. Lang DA, Matthews DR, Ward GM, Burnett M, Turner RC (1982) Pulsatile, synchronous basal insulin and glucagon secretion in man. Diabetes 31: 22-26

8. Stagner JI, Samols E, Weir GC (1980) Sustained oscillations of insulin, glucagon and somatostatin from the isolated canine pancreas during exposure to a constant glucose concentration. J Clin Invest 65: 939-942

9. Lang DA, Matthews DR, Burnett M, Turner RC (1981) Brief, irregular oscillations of basal plasma insulin and glucose concentrations in diabetic man. Diabetes 30: 435-439

10. Warick R, Williams PL (1973) Gray's anatomy, 35th edn. Longman, London

11. Bishop AE, Polak JM, Green IC, Bryant MG, Bloom SR (1980) The location of VIP in the pancreas of man and rat. Diabetologia 18: 73-78

12. Forssmann WG, Greenberg J (1978) Innervation of the endocrine pancreas in primates. In: Coupland RE, Forssmann WG (eds) Peripheral neuroendocrine interaction. Springer-Verlag, New York, pp 124-143

13. Larsson LI, Fahrenkrug J, Holst JJ, Schaffalitzky de M OB (1978) Innervation of the pancreas by vaso-active intestinal peptide immuno-reactive nerves. Life Science 22: 773-80

14. Service FJ, Nelson RL, Rubenstein AH, Go VLW (1978) Direct effect of insulin on secretion of insulin, glucagon, gastric inhibitory polypeptide, and gastrin during maintainance of normoglycemia. J Clin Endocrinol Metab 47: 488-493

15. Toyota T, Abe K, Kudo M, Kimura K, Goto Y (1975) Inhibitory effects of synthetic rat C-peptide on insulin secretion in the isolated perfused rat pancreas. Tohuku J Exp Med 117: 79-83

16. Luft R, Efendic S, Hokfelt T (1978) Somatostatin - both hormone and neurotransmitter? Diabetologia 14: 1-13

17. Albano JDM, Ekins RP, Maritz G, Turner RC (1972) A sensitive, precise radioimmunoassay of serum insulin relying on charcoal separation of bound and free moieties. Acta Endocrinol Copenh 70: 487-509

18. Chatfield C (1975) The analysis of time series: theory and practice. Chapman \& Hall, London
19. Spiegel MR (1972) Theory and problems of statistics. McGraw Hill, New York

20. Moore PG (1969) Principles of statistical techniques, 2nd edn. Cambridge University Press

21. Hoel PG (1966) Introduction to mathematical statistics. Wiley, New York

22. Swed FS, Eisenhart C (1943) Tables for testing randomness of grouping in a sequence of alternatives. Ann Math Stat 14: 66-87

23. Fisher RA (1934) Statistical methods for research workers, 5th edn. Oliver \& Boyd, Edinburgh

24. Whitfield IC (1960) An introduction to electronics for physiological workers. Macmillan, London

25. Lindley DV, Miller JCP (1952) Cambridge elementary statistical tables. Cambridge University Press

26. Judd HL (1979) Biorhythms of gonadotrophins and testicular hormone secretion. In: Krieger DT (ed) Endocrine rhythms. Raven Press, New York, pp 299-324

27. Weitzman RE, Fischer DA, Di Stefano II, Bennett CM (1977) Episodic secretion of argine vasopressin. Am J Physiol 233: E $32-36$

28. Wakerly JB, Lincoln DW (1973) The milk-ejection reflex of the rat: A 20- to 40-fold acceleration of the firing of paraventricular neurones during oxytocin release. J Endocrinol 57: 477-493

29. Clayton RN, Catt KJ (1982) Gonadotropin-releasing hormone receptors. Characterisation, physiological regulation and relationship to reproductive function. Endocrine Reviews 2: 186-209

30. Krieger DT (1979) Endocrine rhythms. Raven Press, New York

31. Matthews DR, DuToit D, Ashcroft SJH, Lang DA, Christie MR, Turner RC (1981) Stability of the pancreatic pacemaker. Diabetologia 20: 672 (Abstract)

32. Matthews DR, Lang DA, Christie MR, Benjamin TB (1981) Insulin oscillations: pancreatic pacemaker and feed-back loops. Diabetologia 21: 303 (Abstract)

33. Turner RC, Holman RR, Matthews DR, Hockaday TDR, Peto J (1979) Insulin deficiency and insulin resistance interaction in diabetes: estimation of their relative contribution by feedback analysis from basal insulin and glucose concentrations. Metabolism 28: 1086-1096

34. Hansen BC, Pek S, Koerker DJ, Goodner CJ, Wolfe RA, Schielke GP (1981) Neural influences on oscillations in basal plasma levels of insulin in monkeys. Am $\mathbf{J}$ Physiol 240: E 5-11

35. Halter JB, Metz SA (1982) Sodium salicylate augments the plasma adrenocorticotrophin and cortisol responses to insulin hypoglycaemia in man. J Clin Endocrin Metab 54: 127-130

36. Terman FE (1943) Radio engineers handbook. McGraw Hill, New York

Received: 7 April 1982

and in revised form: 23 November 1982

Dr. D. R. Matthews

Diabetes Research Laboratories

Radcliffe Infirmary

Woodstock Road

Oxford, UK 